\title{
A meta-analysis of phosphate binders lanthanum carbonate versus sevelamer hydrochloride in patients with end-stage renal disease undergoing hemodialysis
}

\author{
Tianbiao Zhou ${ }^{* 1}$, Hongyan $\mathrm{Li}^{* 2}$, Weiji Xie ${ }^{* 1}$, Zhijun Lin ${ }^{1}$
}

1. Department of Nephrology, the Second Affiliated Hospital of Shantou University Medical College, 515041, Shantou, China.

2. Department of Nephrology, Huadu District People's Hospital of Guangzhou, Southern Medical University, Guangzhou, 510800, China.

*The first three authors contributed equally to this work.

\begin{abstract}
:
Background and Objectives: The purpose of this study was to compare the effects of phosphate binders lanthanum carbonate (LC) versus sevelamer hydrochloride (SH) in end-stage renal disease (ESRD) patients undergoing hemodialysis.

Methods: Studies including randomized controlled trials (RCTs) comparing phosphate binders lanthanum carbonate versus sevelamer hydrochloride, in ESRD patients undergoing hemodialysis, were identified using a pre-defined search strategy. Phosphate, calcium, calcium-phosphorus product, intact parathyroid hormone, alkaline phosphatase, total cholesterol, and triglyceride were extracted and compared by RevMan 5.1 (The Cochrane Collaboration, Oxford, UK).

Results: Six studies were identified. Meta-analysis showed that SH treatment reduced levels of phosphate, intact parathyroid hormone, and total serum alkaline phosphatase (ALP) when compared with LC treatment. Furthermore, patients on SH treatment tended to have reduced calcium levels, calcium-phosphorus product, total cholesterol, and triglyceride when compared to patients treated with LC, but there was no statistical difference.

Conclusion: SH treatment of patients with ESRD is more effective compared to LC treatment. However, more well-designed random control trails are required for confirmation.

Keywords: End-stage renal disease, hemodialysis, phosphate binders, lanthanum carbonate (LC), sevelamer hydrochloride (SH), meta-analysis.
\end{abstract}

DOI: https://dx.doi.org/10.4314/ahs.v18i3.27

Cite as: Zhou T, Li H, Xie W, Lin Z. A meta-analysis of phosphate binders lanthanum carbonate versus sevelamer hydrochloride in patients with end-stage renal disease undergoing hemodialysis. Afri Health Sci. 2018;18(3): 689- 696. https://dx.doi.org/10.4314/abs.v18i3.27

\section{Introduction}

Patients with End State Renal Disease (ESRD) present very late and with cardiovascular complications, and have refractory hypertension, anemia, and other complications, such as chronic kidney disease mineral bone dis-

\section{Corresponding author:}

Tianbiao Zhou, Department of Nephrology, the Second Affiliated Hospital of Shantou University Medical College, 515041, Shantou, China E-mail: zhoutb@aliyun.com order (CKD-MBD), with very high morbidity and mortality ${ }^{1-4}$. High serum phosphorus is linked to poor health and mortality in chronic kidney disease (CKD) patients undergoing dialysis ${ }^{5}$. Kidney Foundation Kidney Disease Outcome Quality Initiative (KDOQI) 2003 guidelines recommend maintaining phosphorus levels between 3.5 and $5.5 \mathrm{mg} / \mathrm{dL}$ in dialysis patients, and more than half of dialysis patients have serum phosphorus levels above the range recommended by the KDOQI ${ }^{6,7}$. Elevated phosphorus is associated with increased mortality in patients with end-stage renal disease (ESRD) ${ }^{8}$. Hyperphosphatemia in patients with ESRD is common among recipients of maintenance dialysis and is associated with a higher risk of mortality and cardiovascular events ${ }^{9}$. Prevention 
or management of rising or high serum phosphate concentrations in CKD patients is now considered to be an important intervention to prevent downstream complications resulting from poor management of serum calcium and parathyroid hormone $(\mathrm{PTH})^{10}$.

Oral phosphate binders are prescribed to CKD patients to prevent the absorption of dietary phosphate, conferring a significant survival benefit to dialysis patients, as does the use of dietary phosphate binders ${ }^{11}$. Currently available binders have been associated with either impaired (calcium-based binders) or beneficial (non-calcium-based binders) outcomes. Commonly used calcium-containing phosphate binders may contribute to calcium overload, potentially increasing the risk of vascular calcification and cardiovascular disease. Lanthanum carbonate (LC) and sevelamer hydrochloride $(\mathrm{SH})$ are two of the most important non-calcium-based binders at present. Non-calcium-containing phosphate binders are advocated for patients with evidence of hypercalcemia, serum parathyroid hormone (PTH) values $<150 \mathrm{pg} / \mathrm{ml}$, and vascular or soft tissue calcification ${ }^{7}$.

However, it has been difficult for the doctors to choose between LC and SH for treatment of ESRD patients. This meta-analysis was performed to assess the difference of phosphate binders LC versus $\mathrm{SH}$ in patients, with ESRD, undergoing hemodialysis.

\section{Materials and methods} Search strategy

The relevant studies were screened, from the search engines of PubMed, Embase, and Cochrane Library as of 31 March 2017, using the search terms "(Lanthanum Carbonate OR LC) AND (Sevelamer Hydrochloride OR $\mathrm{SH})$ " without language limitation. We also extended the search spectrum to the 'related articles' and the bibliographies of all retrieved studies. If multiple publications from the same study group occurred, we only recruited the most complete paper for analysis.

\section{Inclusion and exclusion criteria}

\section{Inclusion criteria}

The inclusion criteria for the study were as follows: (1) study type: randomized controlled trials, randomized crossover study, prospective study, and case control study. (2) Object of the study: all patients who met the diagnostic criteria for ESRD. (3) Interventions: using lanthanum carbonate and sevelamer hydrochloride for treatment, respectively. (4) Baseline information: comparable.

\section{Exclusion criteria}

Exclusion criteria for the study were as follows: (1) only used one drug for the treatment. (2) compared the lanthanum carbonate/sevelamer hydrochloride with other phosphate binders. (3) The diagnostic criteria were not clear.

\section{Outcome measures}

Phosphate $(\mathrm{mg} / \mathrm{dL})$, calcium $(\mathrm{mg} / \mathrm{dL})$, calcium-phosphorus product $\left(\mathrm{mg}^{2} / \mathrm{dL}^{2}\right)$, intact parathyroid hormone $(\mathrm{pg} / \mathrm{mL})$, alkaline phosphatase $(\mathrm{U} / \mathrm{L})$, total cholesterol. $(\mathrm{mg} / \mathrm{dl})$, and triglycerides. $(\mathrm{mg} / \mathrm{dl})$ were used for the outcome measures.

\section{Data collection}

Inclusion of each study was agreed upon by two observers independently according to pre-determined inclusion criteria. Titles and abstracts were scanned first to make a list of possibly related literature, and then the full texts were obtained for those articles identified as either relevant or not clear, only randomized controlled trials, randomized crossover studies, prospective studies, and case control studies fitting the pre-defined inclusion criteria were selected. Disagreements were resolved by other reviewers.

\section{Statistical analysis}

Statistical analysis was performed by RevMan 5.1. The pooled statistics were calculated using the fixed effect model, but a random effect model was conducted if the p-value of the heterogeneity test was less than 0.1 . Results are expressed with odds ratios (OR) for dichotomous data, and weighted mean differences (WMD) for continuous data, and 95\% confidence intervals (CI) were also calculated. Heterogeneity between included studies was tested using the $\chi^{2}$-test.

\section{Results}

\section{Search results}

In this meta-analysis, six studies ${ }^{7,12-16}$ were included, and were comprised of four randomized crossover studies $^{7,12-14}$ and two prospective studies ${ }^{15,16}$ (Table 1). These six studies contained $370 \mathrm{SH}$ cases and $306 \mathrm{LC}$ controls (Table 1). 
Table 1. The detailed characteristics of included studies.

\begin{tabular}{|c|c|c|c|c|c|c|c|c|}
\hline \multirow{2}{*}{$\begin{array}{l}\text { Author, } \\
\text { Year }\end{array}$} & \multirow[t]{2}{*}{ Study type } & \multirow[t]{2}{*}{ Location of study } & \multirow[t]{2}{*}{ Ethnicity } & \multicolumn{2}{|c|}{ Intervention } & \multirow{2}{*}{$\begin{array}{l}\text { Number of } \\
\text { Patients }\end{array}$} & \multirow{2}{*}{$\begin{array}{l}\text { Duration } \\
\text { (week) }\end{array}$} & \multirow{2}{*}{$\begin{array}{l}\text { Dialysis } \\
\text { methods }\end{array}$} \\
\hline & & & & $\mathrm{SH}$ & $\mathrm{LC}$ & & & \\
\hline $\begin{array}{l}\text { Kasai S } \\
2012\end{array}$ & $\begin{array}{l}\text { Randomized } \\
\text { crossover } \\
\text { study }\end{array}$ & Japan & Asian & $750-9000 \mathrm{mg} / \mathrm{d}$ & $375-2250 \mathrm{mg} / \mathrm{d}$ & 84 & 13 & HD \\
\hline $\begin{array}{l}\text { Sprague SM } \\
2009\end{array}$ & $\begin{array}{l}\text { Randomized } \\
\text { crossover } \\
\text { study }\end{array}$ & $\begin{array}{l}\text { USA, Puerto } \\
\text { Rico, Germanyand } \\
\text { the UK }\end{array}$ & Mixed & $4800-6400 \mathrm{mg} / \mathrm{d}$ & $2250-3000 \mathrm{mg} / \mathrm{d}$ & 181 & 4 & HD \\
\hline $\begin{array}{l}\text { Senatore M } \\
2011\end{array}$ & $\begin{array}{l}\text { Randomized } \\
\text { crossover } \\
\text { study }\end{array}$ & Italy & Caucasian & $4800 \pm 800 \mathrm{mg} / \mathrm{d}$ & $3000 \pm 750 \mathrm{mg} / \mathrm{d}$ & 14 & 4 & HD \\
\hline $\begin{array}{l}\text { Filiopoulos } \\
\text { V } 2011\end{array}$ & $\begin{array}{l}\text { Randomized } \\
\text { crossover } \\
\text { study }\end{array}$ & Greece & Caucasian & $2400-7200 \mathrm{mg} / \mathrm{d}$ & $-4500 \mathrm{mg} / \mathrm{d}$ & 14 & 24 & HD \\
\hline Thet Z 2013 & Prospective & Australia & Mixed & NS & NS & 104 & 24 & HD \\
\hline $\begin{array}{l}\text { Prajapati } \\
\text { VA } 2014\end{array}$ & Prospective & Indian & Asian & $400 \mathrm{mg}$ & $500 \mathrm{mg}$ & 60 & 12 & $\mathrm{HD}$ \\
\hline
\end{tabular}

Phosphate levels between the SH- and LC-treated groups

Six reports ${ }^{7,12-16}$ were included in this meta-analysis for the phosphate levels between $\mathrm{SH}$ - and LC-treated groups. The p-value of the heterogeneity test was less than 0.00001 , so a random effect model was conducted. The pooled mean difference was -0.15 ( $95 \%$ CI: -0.29 to -0.02 ). The difference in phosphate levels was statistically significant between SH group and LC group $(p=0.03)$ (Fig. 1).

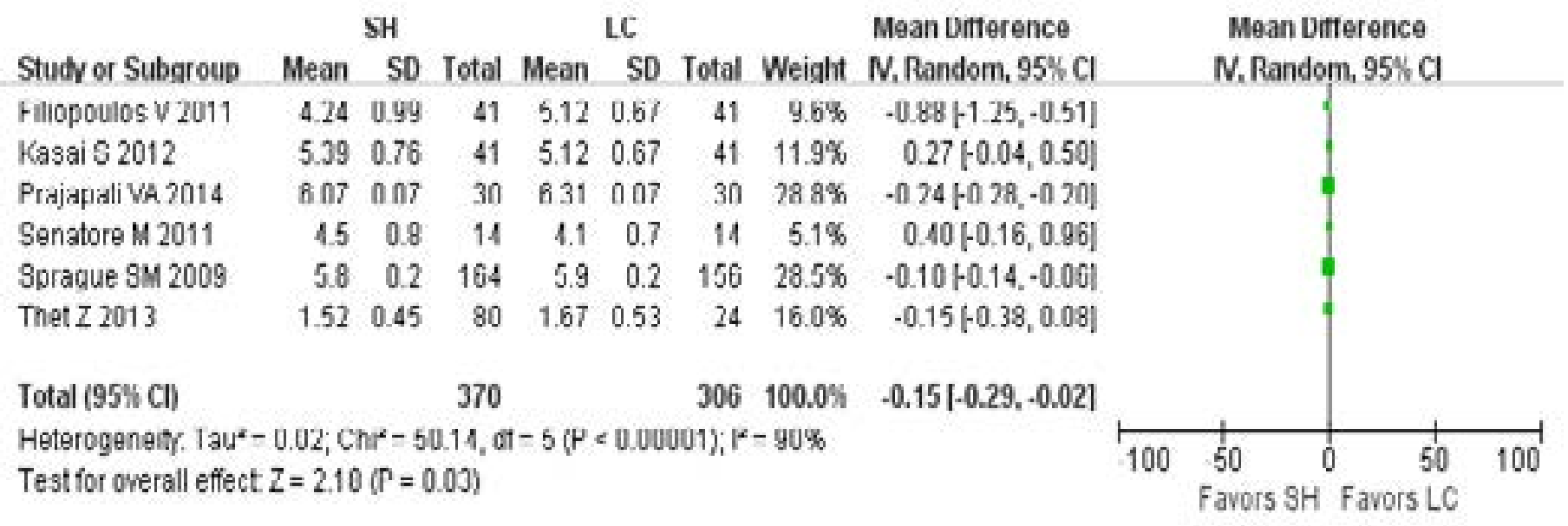

\section{Figure 1. Phosphate levels between the SH-treated and LC-treated groups.}

Calcium levels do not differ between the SH and LC treatment groups

Six reports ${ }^{7,12-16}$ were included in this meta-analysis for the calcium level between the SH-and LC-treated groups. The p-value of the heterogeneity test was less than 0.00001 and a random effect model was conducted. Pooled mean difference was -0.06 (95\% CI: -0.16 to 0.03 ). The difference of calcium levels was not statistically significant between SH group and LC group $(p=0.19)$ (Fig. 2). 


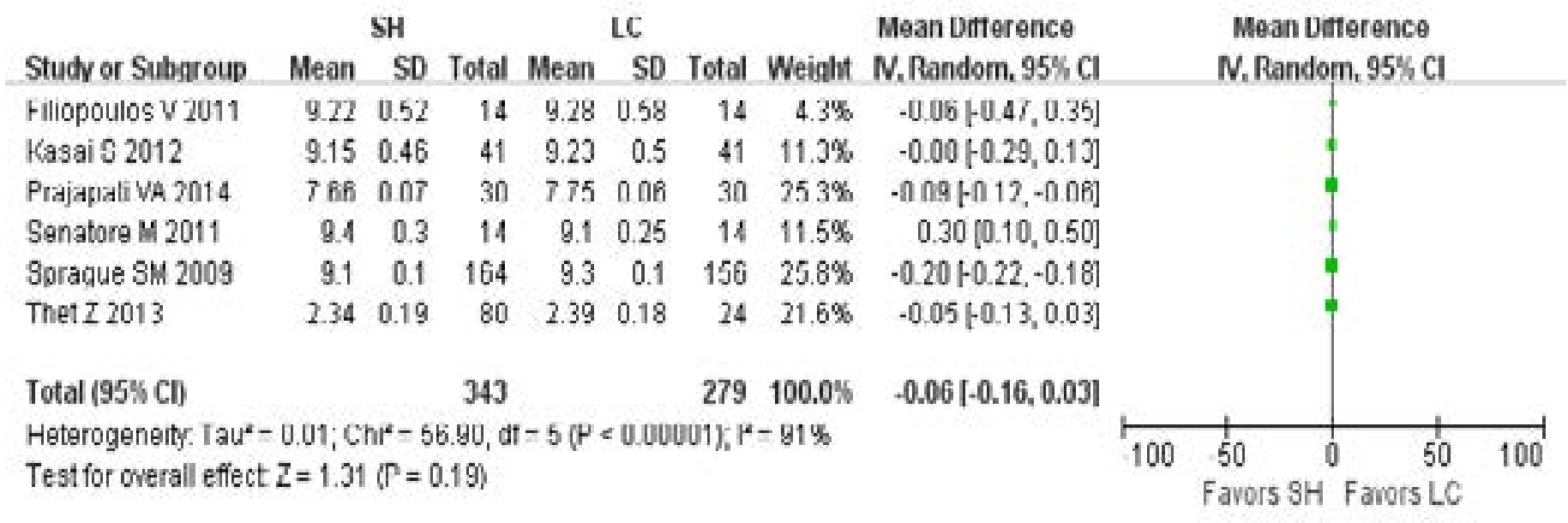

Figure 2. Calcium levels between SH group and LC group

Calcium-phosphorus product levels were similar between the SH and LC treatment groups

Three reports ${ }^{12,14,16}$ were included in this meta-analysis for the calcium-phosphorus product level between SH- and LC-treated patients. The p-value of the heterogeneity test was less than 0.02 , so a random effect model was conducted. The pooled mean difference was -0.76 (95\% CI: -4.14 to 2.61). Differences in the calcium-phosphorus product level were not statistically significant between the SH group and LC group ( $\mathrm{p}=0.66)$ (Fig. 3).

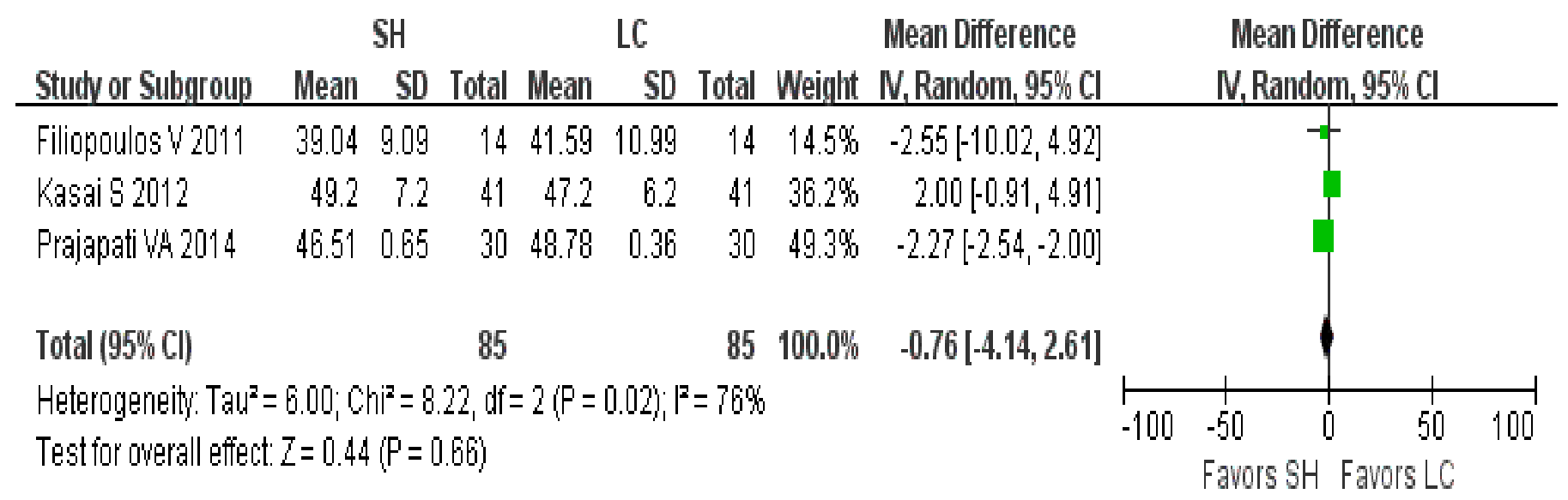

\section{Figure 3. Calcium-phosphorus product between the SH and LC groups}

Intact parathyroid hormone level between $\mathrm{SH}$ group and LC group

Five reports ${ }^{7,12-14,16}$ were included in this meta-analysis for the intact parathyroid hormone level between the $\mathrm{SH}$ and LC groups. The p-value of the heterogeneity test was less than 0.00001, so a random effect model was conducted. The pooled mean difference was -10.19 (95\% CI: -13.36 to -7.01). The difference in intact parathyroid hormone was statistically significant between $\mathrm{SH}$ group and LC group ( $<<0.00001)$ (Fig. 4). 


\begin{tabular}{|c|c|c|c|c|c|c|c|c|c|c|c|c|}
\hline \multirow[b]{2}{*}{ Studv or Subgroup } & \multicolumn{3}{|c|}{ SH } & \multicolumn{3}{|c|}{ LC } & \multicolumn{3}{|c|}{ Mean Difterence } & \multirow{2}{*}{\multicolumn{2}{|c|}{$\begin{array}{l}\text { Mean Datterence } \\
\text { N. Fixed, } 95 \% \text { Cl }\end{array}$}} & \\
\hline & Mean & SD & Total & Mean & SO & Total & Weight & N. Foxed, $95 \% \mathrm{Cl}$ & & & & \\
\hline Fillopoulos Y 2011 & 289.8 & 166.28 & 14 & 311.6 & 225.78 & 11 & $0.0 \%$ & $-21.80[-168.68,125.08]$ & & & & \\
\hline Kasai 82012 & 119.6 & 98.7 & 41 & 133.9 & 98.3 & 41 & $0.6 \%$ & $-14.30[-56.94 .28 .34]$ & & & & \\
\hline Pra|apat WA 2014 & 249.8 & 15.21 & 30 & 263.8 & 11.92 & 30 & $21.1 \%$ & $-14.00[-20.92,-7.08]$ & & $\bullet$ & & \\
\hline Senatore M 2011 & 270 & 80 & 14 & 260 & 75 & 14 & $0.3 \%$ & $10.00[47.44,67.44]$ & & & & \\
\hline Sprताyue SM วnก9 & 2899 & 164 & 164 & 2961 & 18.4 & $15 \hat{6}$ & $780 \%$ & $-920[-1279,-561]$ & & 밈 & & \\
\hline Total $(95 \% \mathrm{Cl})$ & & & 263 & & & 255 & $100.0 \%$ & $-10.19[-13.36,-7.01]$ & & 1 & & \\
\hline $\begin{array}{l}\text { Helerogeneity Chr } \\
\text { Test for overall effec }\end{array}$ & $\begin{array}{l}1.99, \text { dt } \\
z=6.29\end{array}$ & $\begin{aligned}= & 4(\mathrm{P}= \\
& (\mathrm{P} \times 0.00\end{aligned}$ & $\begin{array}{l}.74) ; i^{4} \\
0001)\end{array}$ & $=0 \%$ & & & & & 100 & 500 & $\begin{array}{l}1 \\
\text { Fanors LC }\end{array}$ & 100 \\
\hline
\end{tabular}

Figure 4. Intact parathyroid hormone levels between SH and LC groups

Alkaline phosphatase levels between the SH-treated and LC-treated groups

Two reports ${ }^{12,16}$ were included in this meta-analysis for the alkaline phosphatase level following SH and LC treatment. The p-value of the heterogeneity test was less than
0.95 and a fixed effect model was conducted. The pooled mean difference was -5.04 (95\% CI: -8.06 to -2.03 ). Difference of alkaline phosphatase level was statistically significant between SH group and LC group ( $p=0.001)$ (Fig. $5)$.

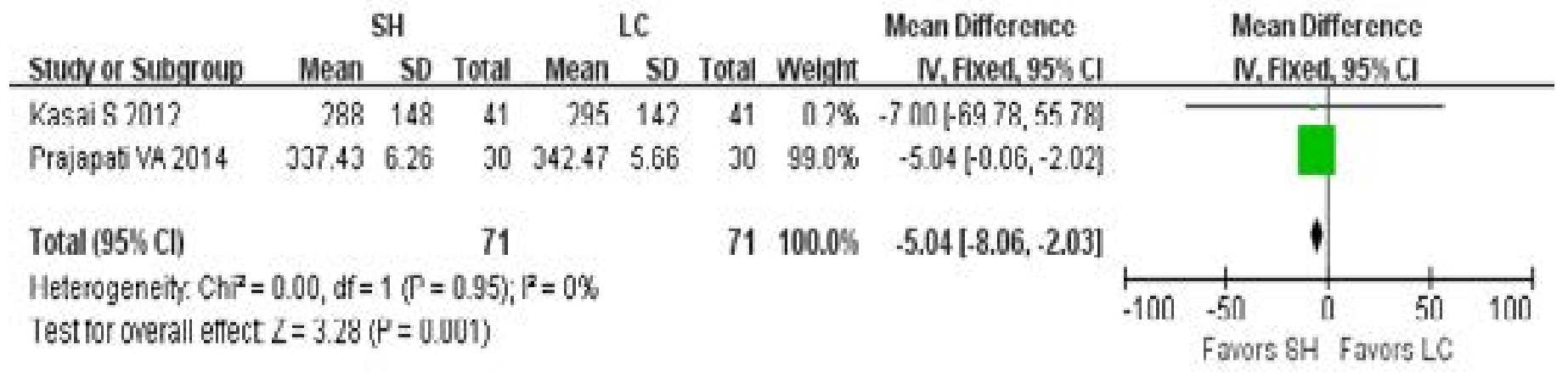

Figure 5. Alkaline phosphatase levels between the SH and LC groups

Total cholesterol levels do not differ between SH-treated and LC-treated patients

Two reports ${ }^{13,14}$ were included in this meta-analysis for the total cholesterol level between SH-treated and LC-treated patients. The $\mathrm{p}$-value of the heterogeneity test was less than 0.96 and a fixed effect model was conducted. Pooled mean difference was -13.64 (95\% CI: -43.14 to 15.87 ). Difference in total cholesterol level was not statistically significant between the $\mathrm{SH}$ and LC groups $(\mathrm{p}=0.37$ ) (Fig. $6)$.

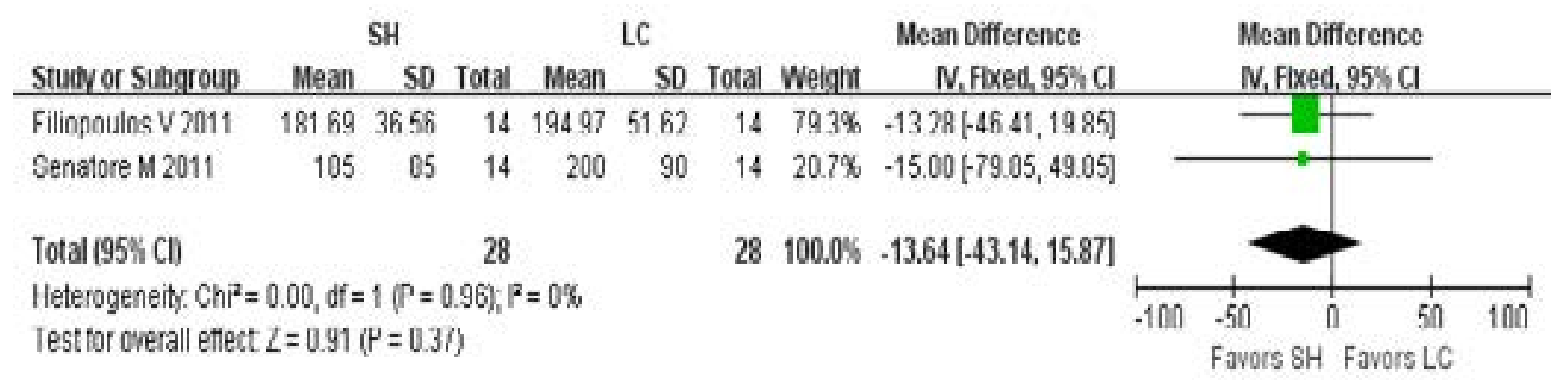

Figure 6. Total cholesterol levels between the SH and LC groups. 
Triglyceride levels between SH- and LC-treated patients do not differ

Two reports ${ }^{13,14}$ were included in this meta-analysis for the triglyceride levels following SH treatment vs. LC treatment. The p-value of the heterogeneity test was less than 0.91 , so a fixed effect model was conducted. The pooled mean difference was -4.70 (95\% CI: -26.42 to 17.02). Difference of triglyceride level was not statistically significant between groups ( $\mathrm{p}=0.67$ ) (Fig. 7).

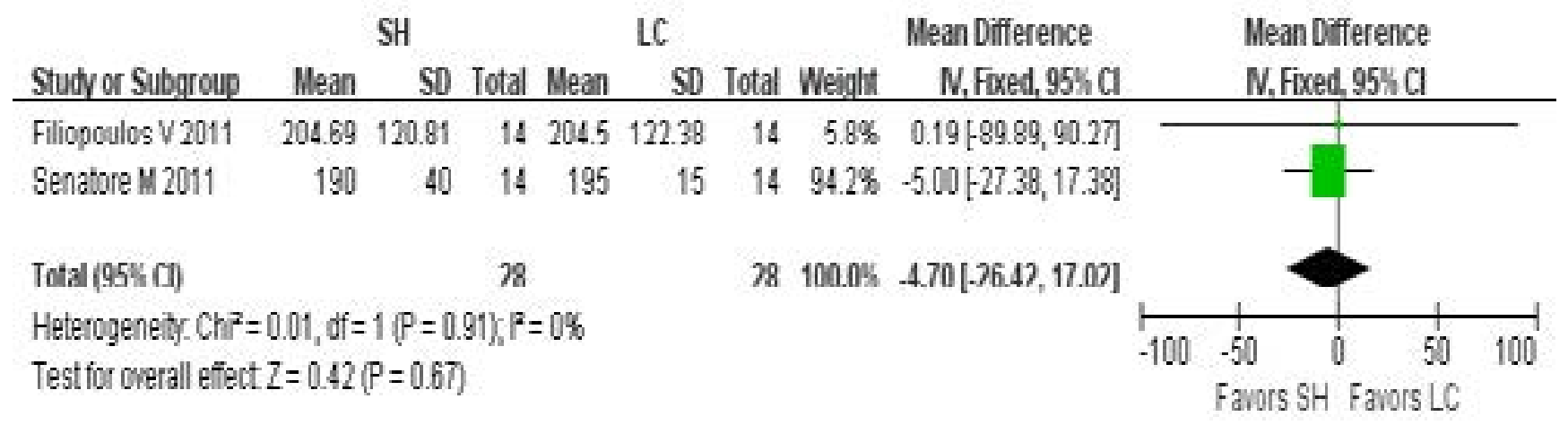

Figure 7. Triglyceride levels between the SH and LC groups.

\section{Discussion}

In this meta-analysis, treatment with $\mathrm{SH}$ was found to lower phosphate levels to a greater extent than treatment with LC. Fixed model comparisons also supported this result, indicating that using $\mathrm{SH}$ to treat CKD patients, to control the phosphate level, is better than using LC. Calcium levels were not statistically different between the $\mathrm{SH}$ and LC groups, but when the fixed model was used to assess this relationship, $\mathrm{SH}$ treatment did appear to lower calcium levels, compared to LC treatment $(\mathrm{p}<0.00001)$. More studies should be performed to confirm this association further.

The calcium-phosphorus product level between the $\mathrm{SH}$ groupand LC group in this meta-analysis indicated that SH treatment tended to lower the calcium-phosphorus product level when compared with LC treatment. However, the difference of calcium-phosphorus product level was not statistically significant between SH group and LC group. However, when the fixed model was used to assess this relationship, SH treatment the difference in calcium-phosphorus product level was statistically significant between SH group and LC group $(\mathrm{p}<0.00001)$. More studies should be performed to confirm this association in the future.
Increased intact parathyroid hormone level is one of the most important risk factors for ESRD patients. In this meta-analysis, we found that the SH treatment could lower PTH levels as compared to LC treatment. Lowering of PTH by SH was confirmed in the fixed model, indicating that treating ESRD patients with SH can control PTH level better than LC.

Elevated total serum alkaline phosphatase (ALP) levels have also been associated with mortality in both the general population and in dialysis patients ${ }^{17}$. Therefore, in this meta-analysis, we examined ALP levels in SH-treated and LC-treated patients. We found that both the mean difference and fixed model show SH lowers ALP levels to a greater extent than LC. Therefore, using $\mathrm{SH}$ to treat CKD patients should better control ALP levels than using LC.

Examination of total cholesterol level, another risk factor for patients with ESRD, showed that the difference of total cholesterol level is not statistically significant between SH-treated vs. LC-treated patients. However, the pooled mean difference and fixed model indicate that the SH could lower total cholesterol level to a greater extent than LC. However, there were only two included studies for the meta-analysis on total cholesterol level. 
Commonly elevated triglyceride levels are also a risk factor for the patients with ESRD. In this meta-analysis, there was no heterogeneity among the included studies, and the fixed model was chosen. The results from the pooled mean difference indicated the difference of total triglyceride levels was not statistically significant between SH group and LC group. There were only two included studies for the meta-analysis on total triglyceride levels.

$\mathrm{SH}$ and LC, non-aluminum and non-calcium phosphate binders, are used to prevent hyperphosphatemia without causing elevated serum calcium and causing and accelerating vascular calcification in CKD patients ${ }^{18-20}$. They bind with dietary phosphorus in the gastrointestinal tract and interrupts mucosal absorption. There is minimal absorption of SH and LC into the gastrointestinal mucosa; therefore, its use in clinical practice does not cause organ failure $^{18,21}$. Alam et $\mathrm{al}^{22}$ reported $\mathrm{SH}$ to be superior to calcium-based phosphate binders in reducing serum calcium, phosphate, uric acid and LDL cholesterol levels in patient population with advanced renal bone disease, and SH also appears to be well tolerated with no significant side effects. Wang et $\mathrm{al}^{23}$ reported that compared with standard therapy (calcium-based phosphate binders), LC reduced all-cause mortality in patients on hemodialysis but did not decrease the risk of cardiovascular events. The decrease in serum phosphorus level was similar between LC and the calcium-based phosphate binders, but the risk of hypercalcemia was lower in patients who received LC. There was no meta-analysis to compare the effects of phosphate binders LC versus SH in ESRD patients undergoing hemodialysis using meta-analysis method.

\section{Conclusion}

We conclude that SH treatment in ESRD patients benefits more, compared to LC treatment, as based on greater reductions of phosphate, calcium, intact parathyroid hormone, and alkaline phosphatase levels. Furthermore, treatment with $\mathrm{SH}$ would avoid the lanthanum accumulation that occurs when the LC is used to treat ESRD patients for a prolonged time.

We recommend the use of $\mathrm{SH}$ in patients with ESRD. However, more well designed, random controlled Trails should be performed.
Funding: This study was supported by Guangzhou Medical Key Discipline Construction Project.

\section{Declaration of conflict of interest}

The authors report no conflicts of interest. The authors alone are responsible for the content and writing of the paper.

\section{References}

1. Wang Z, Shi W, Liang X, Wang W, Liang J: Association of interleukin 17 / angiotensin II with refractory hypertension risk in hemodialysis patients. Afr Health Sci. 2016, 16(3):766-771.

2. Ye JJ, Zhou TB, Zhang YF, Wang Q, Su YY, Tang JM, Li HY: Levels of vitamin D receptor and CYP24A1 in patients with end-stage renal disease. Afr Health Sci. 2016, 16(2):462-467.

3. Adrian T, Hornum M, Eriksson F, Hansen JM, Pilely K, Garred P, Feldt-Rasmussen B: Mannose-binding lectin genotypes and outcome in end-stage renal disease: a prospective cohort study. Nephrol Dial Transplant. 2018.

4. Ong CY, Low SG, Vasanwala FF, Fook-Chong SM, Kaushik M, Low LL: Incidence and mortality rates of varicella among end stage renal disease (ESRD) patients in Singapore General Hospital, a 12-year review. BMC Infect Dis. 2018, 18(1):118.

5. Calvo MS, Uribarri J: Contributions to total phosphorus intake: all sources considered. Semin Dial. 2013, 26(1):54-61.

6. Mayne TJ, Benner D, Ricketts K, Burgess M, Wilson S, Poole L, Smyth M, Colson C, Krishnan M: Results of a pilot program to improve phosphorus outcomes in hemodialysis patients. J Ren Nutr. 2012, 22(5):472-479.

7. Sprague SM, Ross EA, Nath SD, Zhang P, Pratt RD, Krause R: Lanthanum carbonate vs. sevelamer hydrochloride for the reduction of serum phosphorus in hemodialysis patients: a crossover study. Clin Nephrol. 2009, 72(4):252-258.

8. Okoye JU, Arodiwe EB, Ulasi, II, Ijoma CK, Onodugo OD: Prevalence of CKD-MBD in pre-dialysis patients using biochemical markers in Enugu, South-East Nigeria. Afr Health Sci. 2015,15(3):941-948.

9. Wald R, Rabbat CG, Girard L, Garg AX, Tennankore K, Tyrwhitt J, Smyth A, Rathe-Skafel A, Gao P, Mazzetti A et al: Two phosphAte taRGets in End-stage renal dis- 
ease Trial (TARGET): A Randomized Controlled Trial. Clin J Am Soc Nephrol. 2017, 12(6):965-973.

10. Goldsmith D, Covic A: Oral phosphate binders in CKD - is calcium the (only) answer? Clin Nephrol. 2014, 81(6):389-395.

11. Nastou D, Fernandez-Fernandez B, Elewa U, Gonzalez-Espinoza L, Gonzalez-Parra E, Sanchez-Nino MD, Ortiz A: Next-generation phosphate binders: focus on iron-based binders. Drugs. 2014, 74(8):863-877.

12. Kasai S, SatoK, Murata Y, Kinoshita Y: Randomized crossover study of the efficacy and safety of sevelamer hydrochloride and lanthanum carbonate in Japanese patients undergoing hemodialysis. Ther Apher Dial. 2012, 16(4):341-349.

13. Senatore M, Coppolino G, Papalia T, Greco R, Lofaro D, Bonofiglio R: Does concomitant administration of sevelamer hydrochloride and lanthanum carbonate modify the control of phosphatemia? Eur Rev Med Pharmacol Sci. 2011, 15(11):1352-1354.

14. Filiopoulos V, Koutis I, Trompouki S, Hadjiyannakos D, Lazarou D, Vlassopoulos D: Lanthanum carbonate versus sevelamer hydrochloride: improvement of metabolic acidosis and hyperkalemia in hemodialysis patients. Ther Apher Dial. 2011, 15(1):20-27.

15. Thet Z, Win AK, Pedagogos E, Beavis J, Crikis S, Nelson C: Differential effects of phosphate binders on pre-dialysis serum bicarbonate in end-stage kidney disease patients on maintenance haemodialysis. BMC Nephrol. 2013, 14:205.

16. Prajapati VA, Galani VJ, Shah PR: A comparative study of phosphate binders in patients with end stage kidney disease undergoing hemodialysis. Saudi J Kidney Dis Transpl. 2014, 25(3):530-538.
17. Taliercio JJ, Schold JD, Simon JF, Arrigain S, Tang A, Saab G, Nally JV, Jr., Navaneethan SD: Prognostic importance of serum alkaline phosphatase in CKD stages 3-4 in a clinical population. Am J Kidney Dis. 2013, 62(4):703710 .

18. Shitomi Y, Nishida H, Kusaba T, Daa T, Yano S, Arakane M, Kondo Y, Nagai T, Abe T, Gamachi A et al: Gastric lanthanosis (lanthanum deposition) in dialysis patients treated with lanthanum carbonate. Pathol Int 2017, 67(8):389-397.

19. Zhang C, Wang S, Zhao S, Zhang X: Effect of lanthanum carbonate on coronary artery calcification and bone mineral density in maintenance hemodialysis patients with diabetes complicated with adynamic bone disease: A prospective pilot study. Medicine (Baltimore) 2017, 96(45):e8664.

20. Lin CJ, Pan CF, Chuang CK, Liu HL, Huang SF, Chen $\mathrm{HH}$, Wu CJ: Effects of Sevelamer Hydrochloride on Uremic Toxins Serum Indoxyl Sulfate and P-Cresyl Sulfate in Hemodialysis Patients. J Clin Med Res. 2017, 9(9):765-770. 21. Yamaguchi T, Ohyama S, Furukawa H, Sato N, Ohnishi I, Kasashima S, Kawashima A, Kayahara M: Sigmoid colon diverticula perforation associated with sevelamer hydrochloride administration: A case report. Ann Med Surg (Lond) 2016, 10:57-60.

22. Alam S, Hussain A, Daiwajna R, Tan J: Clinical efficacy of sevelamer hydrochloride in patients with endstage renal disease: a retrospective study. Singapore Med J. 2013,54(5):263-266.

23. Wang F, Lu X, Zhang J, Xiong R, Li H, Wang S: Effect of Lanthanum Carbonate on All-Cause Mortality in Patients Receiving Maintenance Hemodialysis: a Meta-Analysis of Randomized Controlled Trials. Kidney Blood Press Res. 2018, 43(2):536-544. 